\title{
TEMPERATURA VOZ DE MARIANO PEYROU: EMERGENCIAS DESDE LA PHONÉ.
}

\section{TEMPERATURE VOICE BY MARIANO PEYROU: EMERGENCIES FROM THE PHONÉ.}

\author{
Alessandro Mistrorigo \\ Università Ca' Foscari Venezia, Italia \\ alessandro.mistrrigo@unive.it
}

\begin{abstract}
Resumen:
Temperatura voz es el quinto libro de poemas de Mariano Peyrou, autor nacido en Buenos Aires en 1971 y que vive en Madrid desde los 5 años. Se trata de un libro muy particular dentro de la trayectoria de este poeta. Según algunos críticos, se escribió a partir de una idea de poesía relacionada con la música dodecafónica y con un modelo combinatorio. Gracias al estudio de algunas grabaciones con la lectura en voz alta del mismo autor realizadas para el proyecto Phonodia, el ensayo reflexiona sobre la voz física, en la phoné, materia pre-verbal del lenguaje, considerándola la matriz sonora que está en la base de la particular escritura de Peyrou. A través del análisis de la señal acústica realizada con PRAAT, se muestra cómo la voz del poeta que lee estos textos lleva a la superficie el conflicto que ocurre entre serie métrica y serie sintáctica. La forma en que la voz del autor resuelve este conflicto típico del lenguaje poético proporciona preciosas informaciones sobre su escritura.
\end{abstract}

Palabras clave: voz, phoné, análisis acústica, pre-verbal, escritura.

\begin{abstract}
:
Temperatura voz is Mariano Peyrou's fifth poetry book. Born in Buenos Aires in 1971, he has been living in Madrid since he was 5 years old. This book of his is a very particular one within his trajectory. According to some critics, it was written based on an idea of poetic language related to dodecaphonic music and through a combinatorial model. Thanks to the study of some recordings made for Phonodia project where is possible to listen to the poet's voice reading aloud, this essay focuses on the physical voice, on the phoné, the preverbal matter of language, considering it as the sound matrix for the particular Peyrou's poetic writing. Through the analysis of the acoustic signal realised with PRAAT, the essay also shows how the voice of the poet who reads aloud his texts brings to the surface the conflict that occurs between metric and syntactic series. The way in which his voice solves this poetic language specific conflict provides precious information about his writing.
\end{abstract}

Keywords: voice, phone, acoustic analysis, pre-verbal, writing.

Recibido: 06 de abril de 2019

Aceptado: 28 de mayo de 2019 
0. Cuando, el 10 de junio de 2010, Ildefonso Rodríguez presentó el libro Temperatura voz (Pre-Textos, 2010) en el Círculo de Bellas Artes de Madrid ${ }^{1}$, citó una entrevista publicada en el número 11 de la Revista 7de7, de marzo del mismo año, donde el poeta Mariano Peyrou adelantaba algunas claves del libro que estaba escribiendo en aquel momento. A Marcos Canteli, que le preguntaba por su aproximación al poema, el autor español le respondía:

[...] volviendo a hablar de música, opino que lleva más tiempo la formación de un improvisador que la de un intérprete. Eso es lo que hay antes, un entrenamiento riguroso para poder ser espontáneo, para poder discriminar en tiempo real lo que sirve de lo que no. Quiero decir que uno puede llenar un cuaderno de palabras y frases y versos y a partir de ahí construir el poema, montarlo, o hacer el filtrado y el montaje en la cabeza, y que el poema surja "casi al dictado". No creo que esta segunda posibilidad sea mejor. Cada método proporciona resultados particulares, y es válido en función de lo que uno quiera hacer. El próximo libro que voy a publicar es un ejemplo del primer sistema: treinta y siete textos escritos a lo largo de nueve años, con innumerables correcciones, lo más lento que he hecho en la vida. Lo contrario de la improvisación. A lo mejor es porque ahí la unidad es la palabra [y no] la frase. En la música pasa lo mismo: no es difícil improvisar frases, construir un discurso cuyo valor esté en la relación que se establece entre las frases, pero para trabajar con notas hay que pensárselo bien. Bach puede improvisar una fuga, pero pídele a Webern que improvise una pieza de las suyas. (Canteli 2009) ${ }^{2}$

A partir de esta repuesta, Ildefonso Rodríguez empieza su presentación relacionando el quinto libro de poemas de Mariano Peyrou con el lenguaje musical y, en particular, con el jazz y la improvisación, y también con la música dodecafónica, de la que

\footnotetext{
${ }^{1}$ El texto de Ildefonso Rodríguez que encontré publicado en la página Facebook de la editorial Pre-Textos con fecha 22 de junio de 2010, se puede encontrar aquí:

https://www.facebook.com/notes/pre-ttextos/presentaci\%C3\%B3n-del-libro-temperatura-voz-de-marianopeyrou-por-ildefonso-rodr\%C3\%ADguez/126860650684956/ (último acceso: 27/04/2019). A partir de ahora, para las citaciones me referiré a este texto con "Rodríguez 2010".

${ }^{2}$ La Revista Sie7de de Sie7e (www.7de7.net/) ya no se encuentra en internet. Conseguí el texto de la entrevista a Mariano Peyrou directamente de su director, Marcos Canteli, a quien agradezco. Para las citaciones me refiero a esa entrevista con "Canteli 2009".
} 
Webern es uno de los compositores más destacados. En su texto, el presentador anota oportunamente que, en la entrevista a Canteli, Peyrou contraponía "improvisación" a “composición" y "palabra" a "frase”. Además nos recuerda que el mismo poeta es músico, saxofonista, y como tal toca jazz y conoce bien la práctica de la improvisación. En efecto, a la pregunta de cómo se relaciona su concepción de la escritura con la dedicación profesional a la música, el autor de Temperatura voz afirma que "tal vez desde la música se pueda aceptar mejor el conflicto con la referencialidad que plantea toda poesía (no solo la poesía contemporánea, aunque en ésta sea más evidente), porque la música no transmite un sentido, es necesariamente abstracta" (Canteli 2009).

La sospecha de Rodríguez, entonces, es que Temperatura voz sea un libro dodecafónico y que su título -bastante enigmático, según Daniel Samoilovich, quien prologa la traducción italiana editada por Alessio Brandolini- se podría leer, afirma, "como Temperamento voz o Voz temperada" (Rodríguez 2010). En efecto, el término temperatura deriva del latín temperare, que no solo significa "tener moderación", "mezclar", "templar" en el sentido de "observar la justa medida" y, por lo tanto, "regular"; sino que, en el léxico específico de la música, lo encontramos como un sinónimo de "afinar" un instrumento. Además, la palabra temperatura se forma con el sufijo -ura que se refiere al "objeto para" o al "resultado de" la acción de temperare. En otras palabras, no se trata de resolver el problema del título añadiendo algún conector lingüístico logrando opciones como "la temperatura de la voz" o "la voz de la temperatura" (Samoilovich 2010: 5), sino tal vez escuchar cómo, ya desde el título de su libro, Mariano Peyrou apunta al ejercicio de temperatura al que ha sometido su "voz" lírica, su lenguaje, su escritura poética.

No cabe duda de que Temperatura voz es un ejercicio de indagación poética del y en el lenguaje, de y en la escritura que a través del substantivo "voz" se encuentra explicitado ya en el mismo título. Siempre explicando este segundo término, Samoilovich escribe que Peyrou habría podido transformar el substantivo "voz" en otra cosa, por ejemplo en un número, indicando un determinado nivel de temperatura (como si dijera: “Temperatura 7") o en un adjetivo, como para señalar una determinada clase de temperatura (como si dijera: "Temperatura roja"). Más allá de estas tentativas, también 
Samoilovich se da cuenta de que estamos “davanti a un'alchimia, a una particolare forma di piegare la grammatica affinché la lingua dica quello che normalmente non dice" (Samoilovich 2010: 5). En efecto, estamos delante de una forma muy particular de doblar la gramática, el lenguaje mismo, que viene de un oído particular y que literalmente compone la obra.

La inteligente presentación de Ildefonso Rodríguez continúa indicando la forma interna del libro, una construcción casi completamente modular:

37 piezas o poemas sin título, numeradas y distribuidas en tres secciones casi perfectamente simétricas: 12, 13 y 12 (y, entonces, podríamos leer cada sección como si se tratase de un poema único). Todas las piezas, excepto dos, son permutaciones, inversiones, retrogradaciones (vuelta metafórica al dodecafonismo) versales y estróficas de una serie fundamental, la más cerrada y fértil de la poesía clásica: el soneto, aquí implosionado hacia un espacio exterior. En la parte o movimiento medio, titulado "No tengo", aparece un poema con 7 versos, la mitad de 14, que se sitúa en el centro mismo, numeral del libro: es su axis, su espinazo (también por lo que nombra: "vienen los nombres"). El otro poema anómalo tiene un dibujo por completo distinto al resto, ofrece una simetría muy marcada de 6 más 6 versos y viene a ser como una pausa formal, un respiro, antes de acometer los últimos 7 poemas del libro. (Rodríguez 2010) ${ }^{3}$

La perfecta tripartición del libro, la forma del soneto implosionado, la sucesión constante de los 14 versos reorganizados siempre en estrofas y números diferentes, las permutaciones y las repeticiones de las palabras formando resonancias internas y continuas, revelan que Temperatura voz está compuesto a partir de una especie de partitura silenciosa y muy estricta que se impone a la materia del lenguaje, a la "voz" que en él se inscribe. A partir de una forma vacía, un molde mudo que precede y se predispone a aceptar la materia lingüística del mismo modo en que un pentagrama acepta las notas según la matemática que subyace a la música "cuando se organiza dentro del orden y desorden de sus formas". ${ }^{4}$ Aquí, después de presentarnos la descripción del molde, de esa

\footnotetext{
${ }^{3}$ https://www.facebook.com/notes/pre-textos/presentaci\%C3\%B3n-del-libro-temperatura-voz-de-marianopeyrou-por-ildefonso-rodr\%C3\%ADguez/126860650684956/

${ }^{4}$ Ibíd.
} 
forma vacía, finalmente Rodríguez se pregunta qué es lo que hay adentro y qué impulso condujo al autor a semejante arrebato compositivo.

En su discurso, Rodríguez no proporciona ninguna respuesta, simplemente nos advierte que la escritura que está en juego en Temperatura voz es algo nuevo en relación a los libros anteriores de Mariano Peyrou. Nacido en Buenos Aires en 1971, a los cinco años tuvo que trasladarse con su familia a Madrid, donde actualmente vive y trabaja de profesor de Escritura Creativa, Historia del Jazz y Estética de la Música. Hasta Temperatura voz, Mariano Peyrou había publicado cuatro libros, La voluntad de equilibrio (Fundación María del Villar, 2000), A veces transparente (Bartleby Editores, 2004), La sal (Pre-Textos, 2005) y Estudio de lo visible (Pre-Textos, 2007). Por otra parte, posteriormente aparecieron las colecciones Niños enamorados (Pre-Textos, 2015) y El año del cangrejo (Pre-Textos, 2017), ambos igualmente diferentes del estricto ejercicio al que el autor sometió su escritura con Temperatura voz.

Un ejercicio desde luego peculiar que, a mí manera de ver, va más allá de la reflexión metapoética sobre el lenguaje. Aunque muy importante, no es suficiente individuar el molde vacío, la forma sigilosa en que la voz poética del autor se inscribe. Si queremos enfrentarnos críticamente a este libro, es necesario indagar qué tipo de "voz" ha podido encontrar su lugar en los textos que nos presenta según ese esquema compositivo que, como ocurre en el sistema musical que divide la octava en doce partes absolutamente iguales, parece dividir el discurso en sus partes mínimas, las palabras - “[...] ahí la unidad es la palabra" (Canteli 2009) - y utilizarlas como notas, como elementos primariamente rítmicos y musicales, casi solo por su valor semiótico, yendo tal vez un poco más allá de su valor referencial. De ello, de la misma materia de que está hecho el lenguaje, de la "voz" misma, entonces, surgiría el sentido de Temperatura voz.

1. El 10 de agosto de 2017, tuve la oportunidad de entrevistar al poeta Mariano Peyrou en su casa de Madrid. La entrevista surgió a raíz de mi trabajo para el proyecto Phonodia (http://phonodia.unive.it), un archivo digital en el que se pueden escuchar las voces de poetas contemporáneos, no solamente españoles, leyendo algunos de sus poemas. Recogí esta entrevista en un libro titulado Phonodia. La voz de los poetas, uso crítico de 
sus grabaciones y entrevistas (Edizioni Ca’ Foscari, 2018), donde se encuentran también unas conversaciones que tuve con otros poetas españoles contemporáneos. En aquella ocasión, antes de empezar la entrevista, Mariano Peyrou leyó en voz alta algunos de sus poemas para que yo los pudiera grabar y luego colgarlos en la página del proyecto. Aquellas grabaciones se pueden escuchar en el siguiente enlace: http://phonodia.unive.it/people/mariano-peyrou/.

La entrevista empezó justo después de la lectura en voz alta y mis preguntas se centraban precisamente sobre el ejercicio que acabábamos de realizar. En realidad, lo que sobre todo me interesaba era entender qué era lo que pensaba el poeta con respecto a su voz física, cuál era la conciencia que él tenía de ese fenómeno, si y cómo podía considerarlo un elemento importante en su proceso creativo; es decir, cuál era el rol que su voz física tenía en relación al texto poético. La charla con Mariano Peyrou fue de las más interesantes y, al preguntarle cómo era su relación con la lectura en voz alta, refiriéndose a un momento anterior de su trayectoria poética me comentó: “pensé que lo que tenía que hacer [al leer en voz alta] era tratar de neutralizar todo lo posible, de neutralizar todo, [...] cualquier cuestión afectiva, cualquier cuestión geográfica, $[\ldots]$ no interpretar, que no haya nada psicológico en el timbre o en la voz [...] tratar de buscar esa especie de objetividad" aunque, sin embargo, “siempre supe que eso era una utopía” (Mistrorigo 2018, 187).

La forma de leer en voz alta de Mariano Peyrou es muy interesante, precisamente porque es un autor que, aunque no escriba pensando en la versión vocal de sus textos “escribo poesía para que entre por la vista" (Mistrorigo 2018, 187) -, siempre percibió el problema ínsito en ese tipo de lectura llegando con los años a un cierto equilibrio. Ahora, dice, "cuando me pongo a leer trato de abstraerme de todo y meterme en el texto y de dejar que salga lo que salga" (Mistrorigo 2018, 188). Peyrou es perfectamente consciente de que "cada letra tiene un montón de connotaciones y algunas de ellas tienen que ver con el sonido, con cómo suenan” (Mistrorigo 2018, 188), aunque afirma que quizás le interesen más sus connotaciones visuales. En la entrevista se refiere también al concepto barthesiano de scriptum, el placer de la escritura con la mano, "algo que tiene que ver con lo material de las letras" y que "es anterior al placer del significado" (Mistrorigo 2018, 189).

En efecto, volviendo a decir que su escritura "es colocar palabras sobre la página" (Mistrorigo 2018, 189) -lo cual confirmaría la composición modular de Temperatura voz, 
con la página como molde vacío, como pentagrama- confiesa que una de las cosas que más le interesan en la poesía es:

la relación entre el verso y la frase. O sea, cómo se cortan las frases formando versos o como se suman a veces las frases formando versos, esa relación totalmente antinatural me parece muy interesante. Y es una relación visual: cuando leo en voz alta mis poemas trato de reproducirla a veces, pero a veces no. (Mistrorigo 2018, 189)

Esa relación visual a la que se refiere Peyrou tiene que ver con la versificación de un texto, con cómo se colocan las palabras de las frases dentro o más allá de los versos de un poema. Aquí están en juego dos elementos fundamentales del lenguaje poético: el encabalgamiento y la cesura o pausa. Con respecto a estos elementos, es interesante la reflexión de Giorgio Agamben quien, en un breve ensayo titulado "Idea de la prosa", muestra la íntima discordancia que existe en el lenguaje de la poesía (Agamben 1989, 22) entre el elemento métrico y el elemento sintáctico y, en particular, entre sonido y sentido, entre phoné y lógos, voz y texto. Donde el encabalgamiento supondría una concesión a la sintaxis que, gracias al avanzar de la voz, se proyecta más allá del verso, la cesura impondría un alto, un instante de pausa y de silencio que bloquea ese impulso y confiere (o dicta) el tiempo en el sentido rítmico abriendo un espacio para la reflexión. Esto sería el tiempo de una-aunque mínima-epojé del verso, una epojé de la poesía.

La manera calma, muy pausada y sin grandes alteraciones de frecuencia o volumen, en la que Mariano Peyrou lee los textos de Temperatura voz, nos revela que, al leerlos, el autor hace mucho caso al silencio, sobre todo al final del verso. Esto tal vez nos indica que, en su escritura, realizó una elección en favor de la cesura, en favor del verso en tanto que elemento métrico, en tanto que molde vacío. Esta elección es clara ya que en algunos casos, allá donde hay el límite versal, también las frases aparecen cortadas. En Temperatura voz, de hecho, muchos versos terminan con una preposición o un adjetivo y, por lo tanto, indicarían el lugar de un encabalgamiento, que la voz tendría que seguir con su movimiento prosódico, encabalgamiento que, sin embargo, en las grabaciones la voz del poeta no ejecuta, no lee. El mismo afirma que en ese libro: 
[...] no solamente hay versos que terminan con una preposición, sino que también hay algún poema que termina con una preposición. Que un verso termine con una preposición es un encabalgamiento entre dos versos, pero que un poema termine así es más, no sé cómo decirlo, es darle un lugar a la preposición, o quitárselo, mejor dicho: es quitarle su función original o su función principal de conexión entre dos ideas. (Mistrorigo 2018, 191)

Quitarle la función gramatical a una preposición significa quitarle el sentido dentro del sistema lingüístico al que se refiriere, quiere decir desnudarla de su rol sintáctico, extraerla de la serie semántica de la lengua a la que pertenece para entregarle un lugar diferente precisamente a partir de lo que queda, es decir, de la materia sonora que la compone, que constituye aquella específica palabra. Ésta es la "materia ( $v \lambda \eta)$ della lingua" (Agamben 2016, 41) de la que habla Aristóteles y que viene del paradigma platónico de una chôra como "puro aver-luogo" (Agamben 2016, 41), algo que "offre un luogo a tutte le forme sensibili, senza però mai confondersi con queste" (Agamben 2016, 41-42). Recuperando el término de Platón, también Julia Kristeva llama chôra semiótica (2006, 28) a esta misma materia sonora que llega de la "sfera preverbale e inconscia, non ancora abitata dalla legge del segno, dove regna l'impulso ritmico e vocale [...] essa precede il sistema simbolico del linguaggio: sfera del semantico dove regna la sintassi e il concetto" (Cavarero 2003, 148). Es a esta misma materia que constituye todas las palabras -las notas- de sus textos a la que el poeta intenta, pues, temperar su voz.

2. De Temperatura voz, en total Mariano Peyrou leyó en voz alta unos once textos. De la homónima primera parte tenemos las grabaciones de los primeros cuatro textos y de la última parte, titulada "Emergencia", las de los poemas I, II, III, VI, X, XI y XII. Lo que se nota al escuchar estas grabaciones ${ }^{5}$ es que, en su lectura, casi nunca hay encabalgamientos. Al contrario: como ya se ha dicho, su voz casi siempre se para al final del verso, aunque éste termine con una preposición o un adverbio. En estos puntos, siguiendo la sintaxis de la frase, la voz debería continuar su trayecto para que la frase se complete y tenga sentido. Sin embargo, la voz de Mariano Peyrou se detiene, se bloquea y el resultado es una lectura versal que corresponde a la disposición visual del texto y que, a

\footnotetext{
${ }^{5}$ http://phonodia.unive.it/people/mariano-peyrou/ (último acceso: 03/05/2019)
} 
veces, incluso fragmenta el mismo verso. Los bloques fónicos producidos por la voz del autor corresponden al verso, generalmente breve, y surgen dentro de ese molde de silencio que está por debajo y determina la escritura poética abriendo un espacio bastante áspero para la voz.

Me acuerdo que cuando escribía [la primera parte de Temperatura voz] pensaba mucho en otra dimensión. Estamos hablando del ojo y del oído, pero hay otra cosa que es el tacto de las palabras, y yo veía muchísima aspereza en ese poema y quería trabajar con la aspereza antes de escribirlo, era como una idea que tenía previa a la escritura. Quería que fuera áspero, no sólo por el sonido, sino por la sintaxis, por el encabalgamiento y por el vocabulario también. Es que hay palabras más ásperas que otras, unas sintaxis más ásperas que otras. (Mistrorigo 2018, 192)

La aspereza se nota especialmente en la forma en que Mariano Peyrou decide plasmar vocalmente la primera parte de su libro. En las grabaciones de los primeros cuatro textos de esta parte, en total, su voz solo produce dos encabalgamientos, ambos en el poema II. Estos encabalgamientos resultan bastante fáciles de detectar al simple oído y, sin embargo, para tener un mayor grado de seguridad he decidido utilizar también el programa PRAAT $^{6}$ con el que se puede visualizar el espectrograma de la voz grabada y, entre otras cosas, analizar la entonación, la intensidad o el volumen. Ofrezco a continuación la trascripción del poema entero con algunos signos, que podríamos definir agógicos, que quieren mostrar el movimiento que la voz del autor imprime a la versificación del poema. En este sentido, he utilizado el signo menor > para indicar el punto donde se verifica un encabalgamiento, cuando la voz no se detiene al final de un verso sino que sigue su movimiento prosódico pasando al verso siguiente, y la barra vertical | para indicar una pausa en este movimiento, cuando se verifica una cesura, un corte en el avanzar prosódico de la voz del autor durante la lectura.

\section{II}

bajo la arena insecta hay un calambre | un picor | un gemir intermitente |

\footnotetext{
${ }^{6}$ PRAAT es un software gratuito para el análisis científico del habla diseñado y desarrollado por Paul Boersma y David Weenink de la Universidad de Ámsterdam y que se puede bajar libremente de la red: http://www.fon.hum.uva.nl/praat/ (último acceso: 1-5-2019).
} 
diálogo del aliento y la resina |

y la tela mojada |

5 ahora verde opaco como otra semana >

sin salir a la nieve |

mano cuarteada siete >

dedos escarbando las fisuras sensibles |

una araña en la pared |

10 un vaso en la mano |

sangre por el suelo |

lame a la salud del silogismo |

la arena la morada inicial |

suelo | patria de nosotros |

Las dos imágenes siguientes, producidas con el programa PRAAT, se refieren a los puntos de la grabación donde se producen los encabalgamientos que se han detectado escuchando la lectura del poema. La primera imagen [fig. 1] se refiere al encabalgamiento que ocurre entre el verso $5 \mathrm{y}$ el verso 6, mientras que la segunda [fig. 2] visualiza el movimiento de la voz entre los versos 7 y 8 .

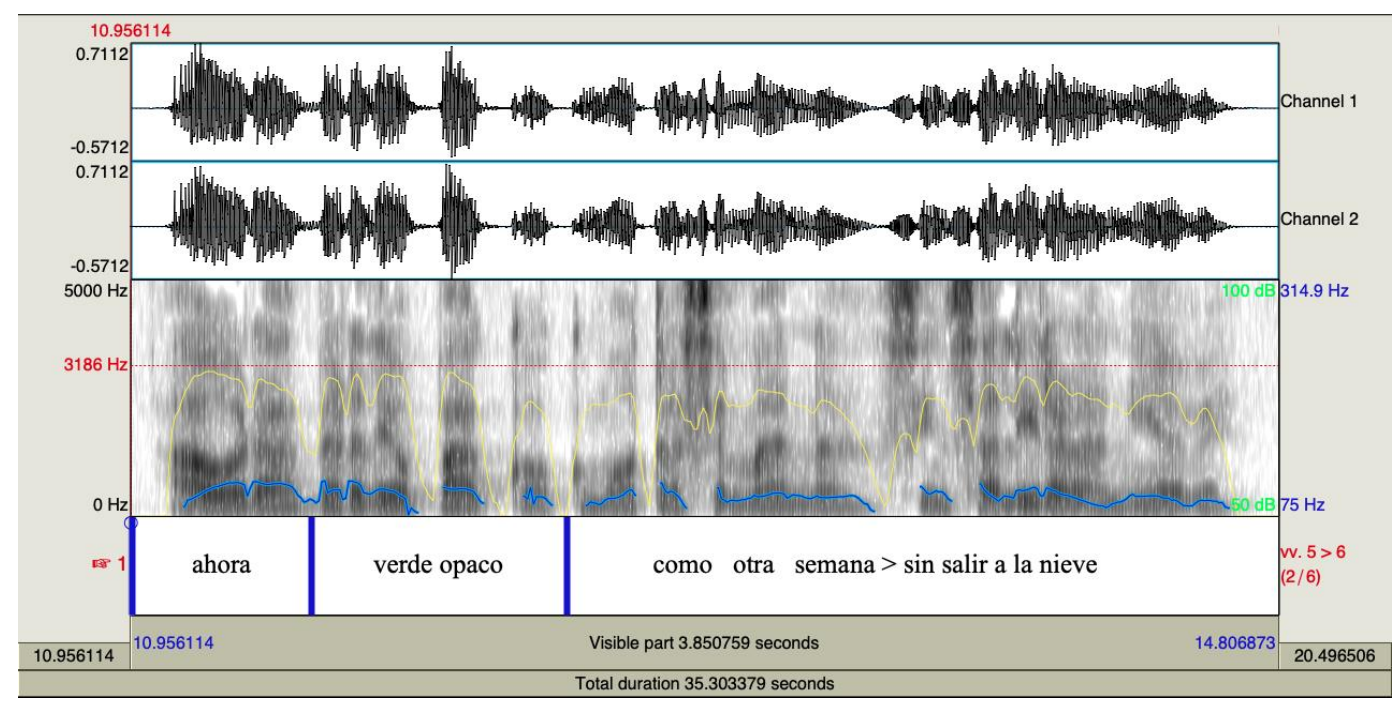

Fig. 1

En la parte baja de la imagen se encuentran las palabras de los versos que nos interesan colocadas en correspondencia con sus articulaciones fónicas: las barras azules delimitan su espacio de articulación y el signo menor > está colocado debajo del punto en 
que cambia el verso. Desde esta imagen, se puede notar que el bloque fónico es prácticamente unitario y corresponde a la suma de los versos 5 y 6 del poema, y que no hay una verdadera pausa en correspondencia del final del verso 5. Al contrario, la voz del autor tiende a vocalizar los dos versos con una cierta continuidad y aunque en el punto del encabalgamiento la línea del pitch se muestre descendente, la intensidad no llega al valor de 0 dB. Lo mismo ocurre también entre los versos 7 y 8.

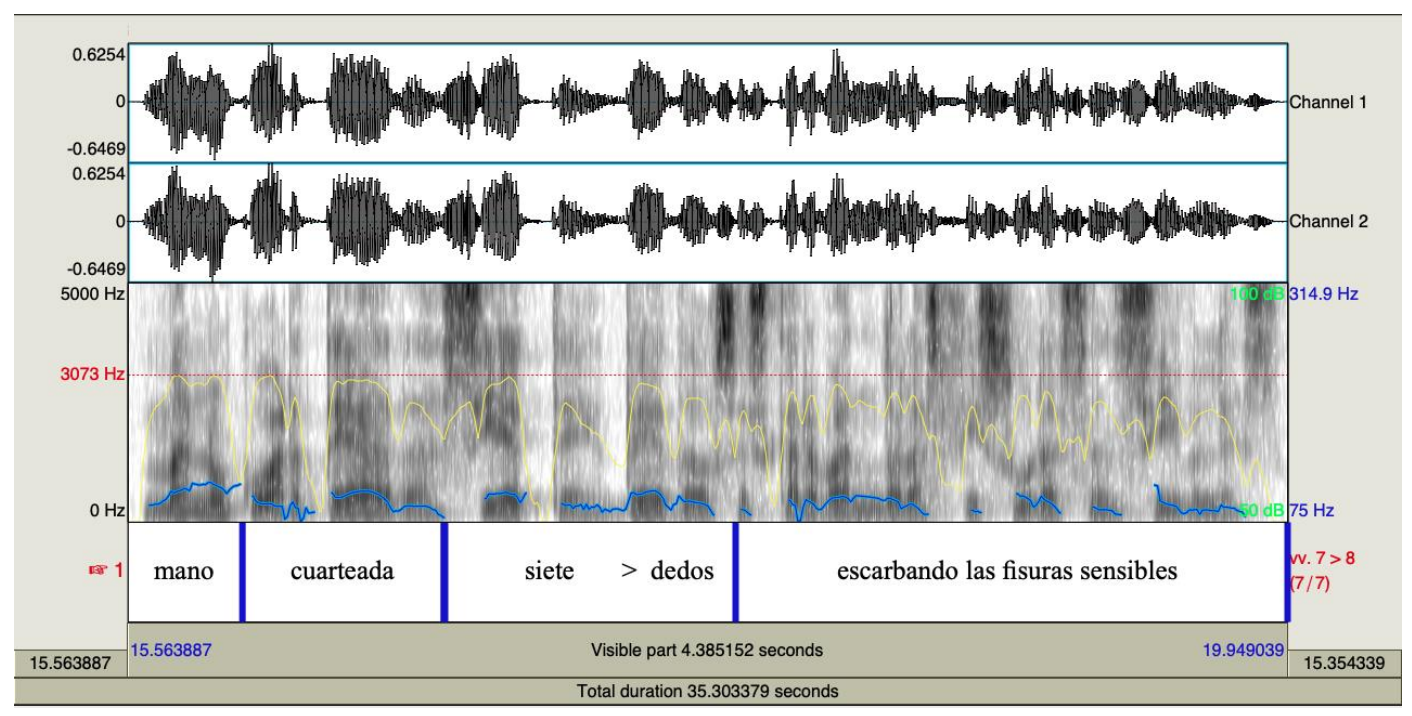

Fig. 2

Aquí no hay ninguna pausa. Tampoco hay dudas de que el bloque fónico marcado por la voz del autor corresponda a la suma de los versos 7 y 8 . Además, en correspondencia con el cambio de verso, el tono se muestra ascendente y continuo a pesar de que baje la intensidad. Este elemento del tono ascendente a final de verso allá donde podría haber un encabalgamiento es, a mí manera de ver, lo más interesante de la forma en que la voz de Mariano Peyrou articula sus poemas en estas grabaciones. Se trata de la estrategia con la que el autor intenta, vocalizando su propio texto, dar constancia a quien lo escucha del conflicto entre la serie sintáctica y la serie métrica (Tsur 2012, 217), entre la frase y el verso, que recorre todo el libro. En aquellos puntos donde, generalmente a final de verso, se articula esta elección entre seguir fielmente el vacío molde semiótico (el verso) y construir un sentido sintáctico más complejo (la frase), la voz del poeta produce unas pausas momentáneas donde, sin embargo, la voz se mueve de forma muy interesante. 
En el primer texto de Temperatura voz, por ejemplo, hay dos momentos en los que la voz de Mariano Peyrou utiliza el tono ascendente justo antes de hacer la pausa de final de verso y poco después empezar a vocalizar el verso siguiente. Estoy hablando del primer verso del poema -y de todo el libro- que termina con la preposición "de" [fig. 3] y del verso 9, donde en posición final se encuentra el adjetivo indefinido "cada" [fig. 4]. Lo interesante aquí es que, aunque haya una pausa evidente detrás de la última palabra de los dos versos, en ambos casos la voz del autor parece extender el sonido de las vocales /e: / y /a: / dándole el tono ascendente como ocurriría si estuviera a punto de producir un verdadero encabalgamiento. En las imágenes producidas con PRAAT este fenómeno se nota bastante claramente. Para trascribir esa forma particular de plasmar vocalmente un encabalgamiento no del todo realizado, he utilizado el signo de la barra inclinada / o de fracción/.

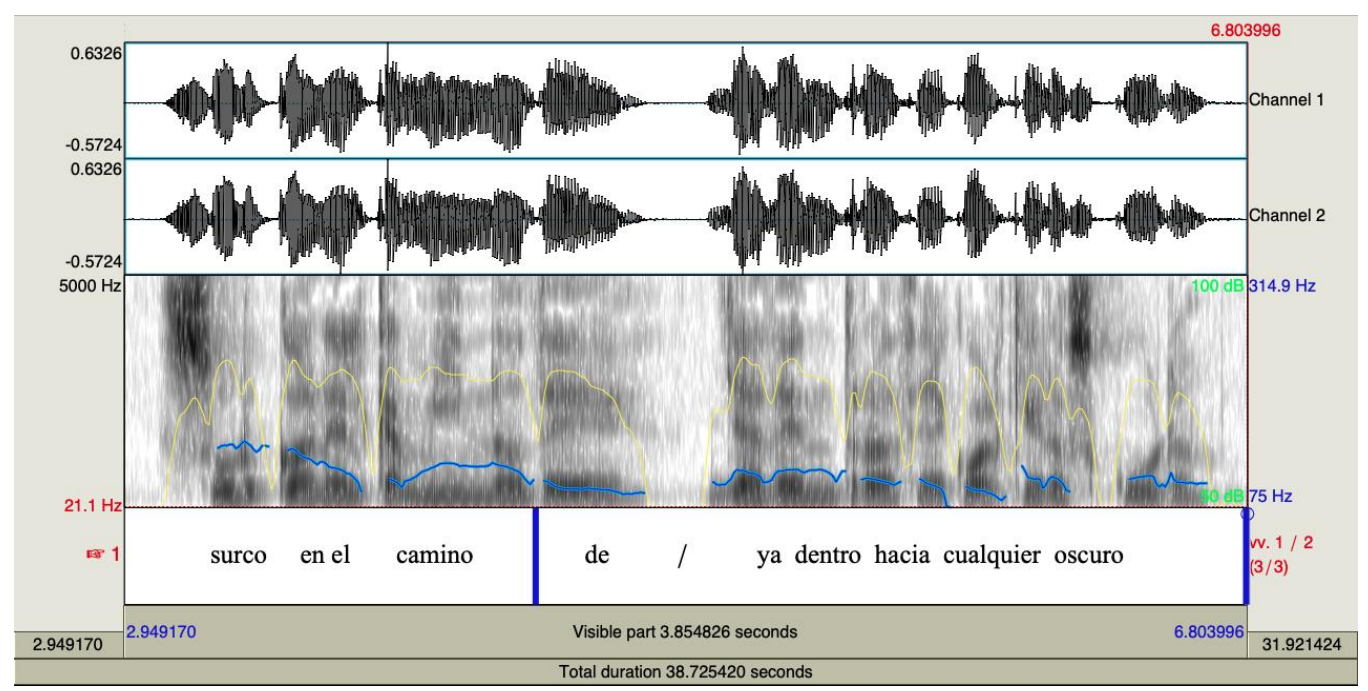

Fig. 3 


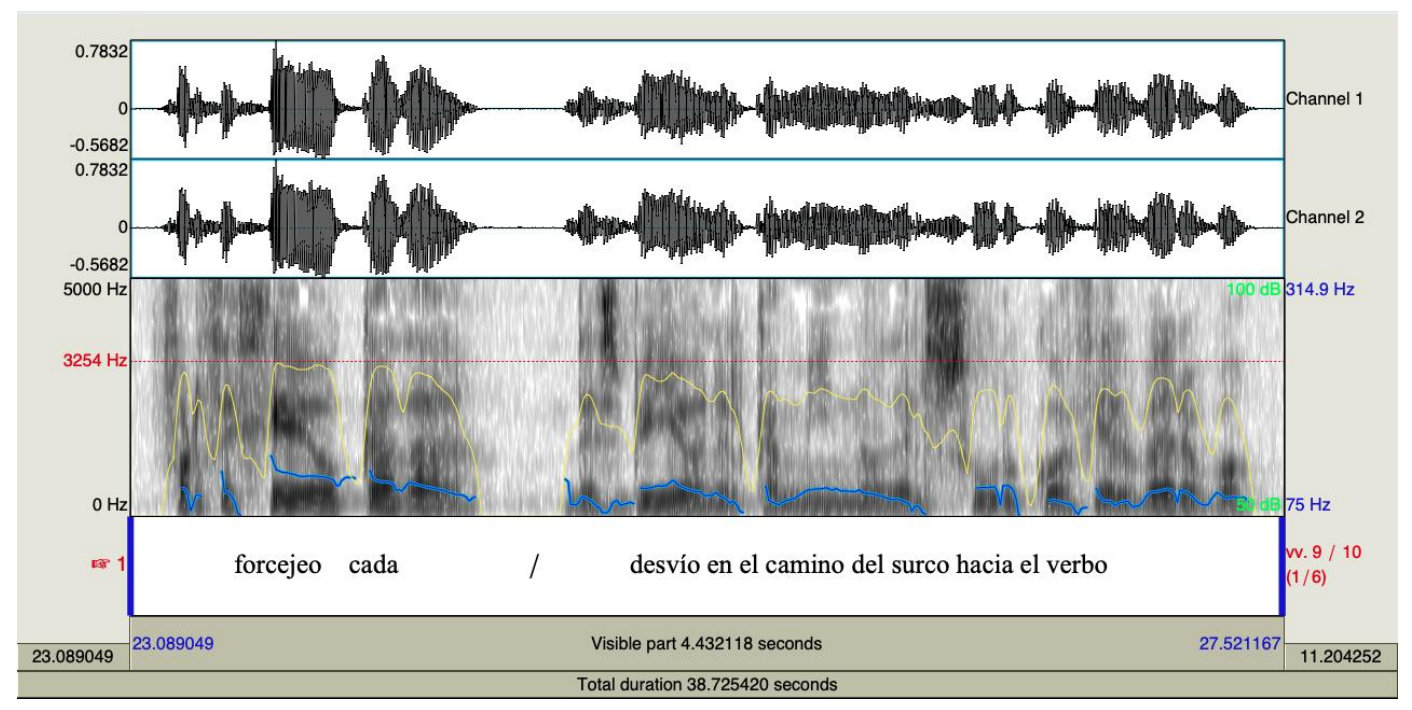

Fig. 4

La voz de Mariano Peyrou actúa de la misma forma en casos parecidos también cuando la palabra con que se concluye un verso termina con un sonido consonántico. En este caso, lo que se escucha es el movimiento de prolongación del último sonido consonántico que generalmente pertenece a una líquida o una nasal. Hay un par de ejemplos que se pueden mostrar desde el poema III y que se producen en los versos 5 y 10 . Ambos terminan con una preposición, es decir, con “en” [fig. 5] y “del” [fig. 6].

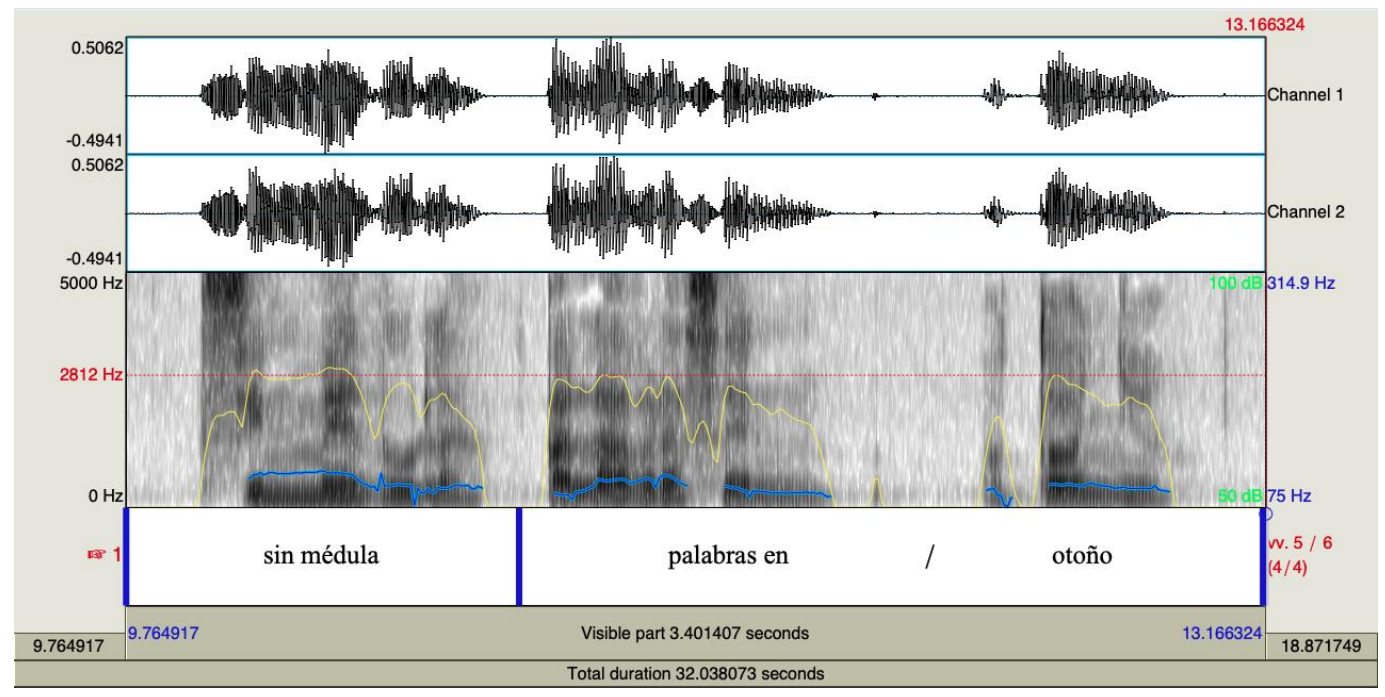

fig. 5 


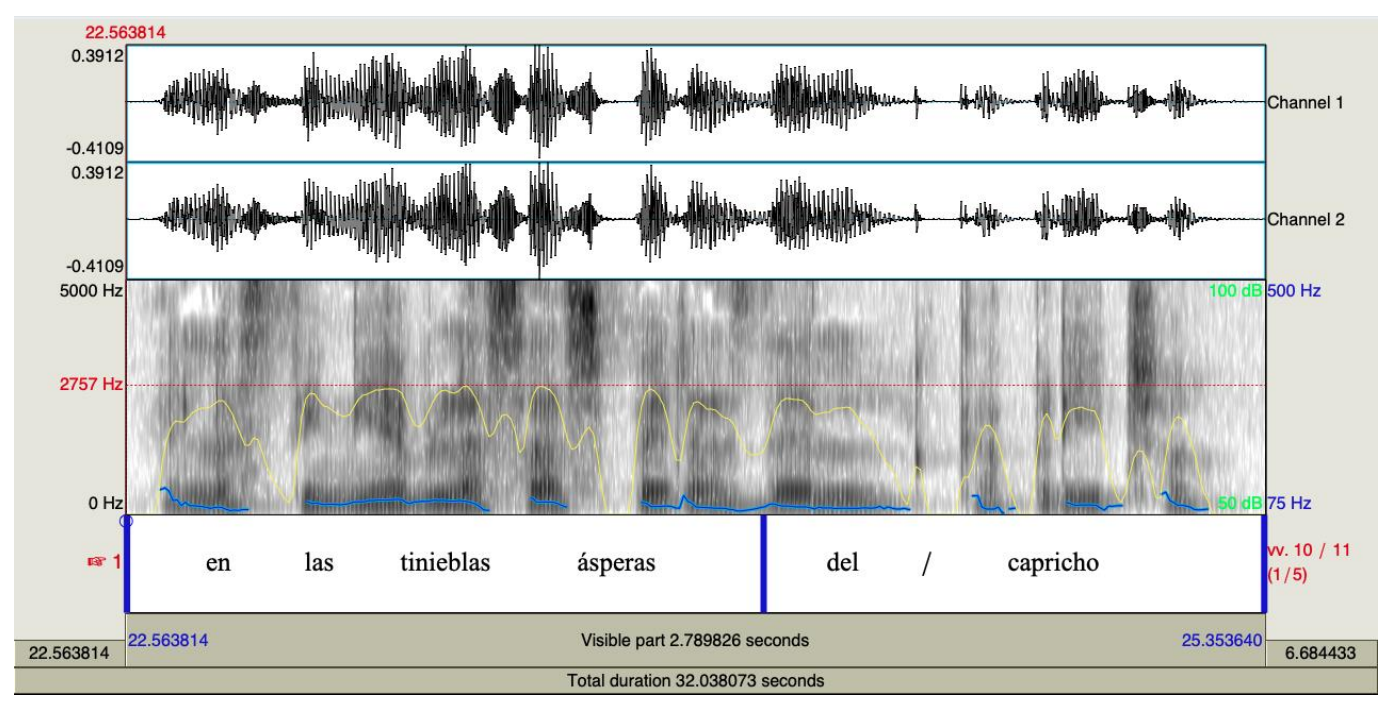

Fig. 6

En la lectura de Mariano Peyrou, este tipo de articulación de la voz recurre siempre en correspondencia de los puntos en que, en posición final del verso, se encuentra una preposición, un adverbio, un artículo, un adjetivo. Es decir, en aquellos puntos donde el sentido sintáctico de la frase empujaría la prosodia más allá de límite versal creando un problema al estricto molde sobre el cual se construye la escritura y evidenciando así sus asperezas. En los primeros cuatro textos de esta primera parte, he escuchado nueve puntos en que, en su lectura, la voz del autor articula un encabalgamiento que se realiza solo "a medias" mostrando la manera de restituir vocalmente la materia sonora en el íntimo desacuerdo entre métrica y sintaxis que, como sugería Agamben, es constitutivo del lenguaje poético.

De hecho, si consideramos la voz como chôra de la lengua, "essa è [...] ciò che, nell'aver-luogo del lógos, percepiamo come irriducibile ad esso, come l'inesprimibile ( $\alpha \pi \varepsilon 1 \rho \circ v)$ che incessantemente, l'accompagna e che, né puro suono né discorso significante, percepiamo all'incrocio fra questi con una assenza di sensazione e con un ragionamento senza significato" (Agamben 2016, 42). En la manera en que la voz física de Mariano Peyrou articula el texto en aquellos puntos donde se cruzan con más dificultad puro sonido y discurso significante, allá se muestra lo que, en tanto que chôra y materia, es un tipo de voz que no se ha escrito nunca en el lenguaje (Agamben 2016, 42) y que, precisamente por ello, siempre continúa actuando en él. 
La voz es «corporeidad del habla», escribe Barthes (1986, 252), y en el acto de su emisión esa voz también proyecta el cuerpo que la produce: es el mismo «cuerpo en la voz que canta, en la mano que escribe, en el miembro que ejecuta» (Barthes 1986, 270). También para el crítico ingles Nowell-Smith, la voz siempre confiere el signo de una presencia biológica y psicológica específica $(2015,5)$ y, en relación a la expresión de una subjetividad particular, en el libro A Voice and Nothing More, el filósofo esloveno Malden Dolar problematiza el concepto de la voz humana que sería un objeto separado bien del lenguaje, bien del cuerpo; aunque venga del cuerpo y le dé sonido al lenguaje, no pertenece ni al cuerpo ni al lenguaje:

voice stands at a paradoxical and ambiguous topological spot, at the intersection of language and the body, but this intersection belongs to neither. What language and the body have in common is the voice, but the voice is part neither of language nor the body. The voice stems from the body, but is not its part, and it upholds language without belonging to it'. (Dolar 2004, 73)

En este sentido, la voz estaría en un espacio vacío entre cuerpo y lenguaje y, como escribe Agamben, articularía «vivente e linguaggio» (1996, 77). En La vita dei copri, el filósofo italiano define el concepto de 'uso' como la relación con un inaprensible (en el texto italiano encontramos el término «inappropriabile», o sea, aquello que no se puede poseer) y en su argumentación analiza tres ejemplos: el cuerpo, la lengua y el paisaje. Con respecto a la lengua materna escribe que:

si presenta per ciascun parlante come ciò che vi è di più intimo e proprio; e, tuttavia, parlare di una 'proprietà' e di una 'intimità' della lingua è certamente fuorviante, dal momento che la lingua avviene all'uomo dall'esterno, attraverso un processo di trasmissione e apprendimento [...] la lingua [inoltre] è per definizione condivisa da altri e oggetto, come tale, di uso comune. (Agamben 2014, 121)

Para reforzar esta idea de la imposibilidad del hablante de poseer la propia lengua, Agamben habla también de la difícil relación de apropiación que persiguen los poetas con respecto a la propia lengua en la transmisión de lo 'propio' que, dice, según una concepción romántica de la poesía (aún vigente) corresponde al 'interior’ del sujeto (los 
sentimientos) que hay que compartir justamente a través de la lengua:

L'appropriazione della lingua che essi [i poeti] perseguono è, cioè, nella stessa misura una espropriazione, in modo che l'atto poetico si presenta come un gesto bipolare, che si rende ogni volta estraneo a ciò che deve essere puntualmente appropriato. (Agamben 2014, 122)

El acto poético, indica Agamben, se muestra como un gesto bipolar en el que aquello que los poetas pretenden poseer - la 'propia' lengua - se les hace cada vez extraño. Este gesto bipolar se ve claramente en la dinámica de la voz en tanto que articulación vacía entre cuerpo y lenguaje, entre phoné resonante y puro lógos. En la lectura en voz alta, entonces, el acto poético se coloca en este campo de fuerza entre posesión y desposesión del lenguaje donde lo que finalmente se activa es aquella voz material, esa chôra informe y material que, precisamente en la intersección entre cuerpo y lenguaje, encuentra su expresión continua. Dentro de esta dinámica toda interna al discurso poético se mueve también la voz física de Mariano Peyrou. Con respecto a esto, me parece interesante mostrar la trascripción del texto IV donde encontramos solo tres puntos en los que hay encabalgamientos "a medias", en los versos 2, 3 y 5, y sin embargo la voz del autor hace un uso mucho más amplio de la cesura.

IV

on/off | es la consigna |

el pulso | el marco el /

secreto la posibilidad del /

ritmo | el cauce de lo estático |

la antítesis del movimiento la /

5 síntesis | pero |

en qué proporción |

frío/calor | y los matices |

que también son el viaje |

lo inscrito sobre el lienzo |

10 lo ya dicho | el pleno baile | tesis saltando los obstáculos | dialécticos | hasta la oscuridad | aparente | 
En este caso, la voz del autor modifica la apariencia visual del texto en la página insertando una gran cantidad de pausas, de silencio, no solamente al final de los 14 versos que componen el soneto implosionado, como lo llama Ildefonso Rodríguez -recuérdese que se produce una pausa en la vocalización también en los casos donde hay un encabalgamiento "a medias"-, sino incluso en la mitad de los mismos y en hasta 7 ocasiones; es decir, en la mitad de los casos, la voz del autor construye o inserta un límite interno a la unidad métrica del verso. En el verso 6, además, la cesura está evidenciada de forma tipográfica con la inserción de un espacio blanco entre las dos palabras que lo componen. Es la única vez que ocurre en todo el libro.

3. El escaso uso del encabalgamiento que hace Mariano Peyrou durante la lectura de estos textos y el uso mucho más frecuente de la cesura es una tendencia que recorre todo el libro. Esto, si seguimos lo que dice Agamben, corresponde a una necesidad de hacer epojé dentro del lenguaje poético. Hacer epojé significa parar el ímpetu prosódico de la voz y dejar tiempo y silencio para que surja la posible reflexión. El molde vacío como método compositivo a priori que percibe Ildefonso Rodríguez y está en la base del libro, le sirve a su autor para estimular esa reflexión del lenguaje poético, para que a partir de ese espacio vacío, ese mudo pentagrama, una materia sonora pueda finalmente inscribirse en él. En esa dimensión espacio-temporal vacía y silenciosa se in-scribe entonces una voz que a su vez lo abre y articula flexionando el camino del lenguaje que vuelve sobre sí mismo. Es ahí, pues, donde el lenguaje, por un momento, por fin se escucha: la abertura a la reflexión -del latín reflecto, 'doblar', 'volver hacia atrás'- del lenguaje que se hace resonancia, reverberación, eco de sí mismo.

En este sentido, entonces, Temperatura voz sería verdaderamente un ejercicio radical que el autor se ha autoimpuesto para afinar el oído en busca de una voz nueva que emerja y encuentre su lugar en la página, «lápiz escribe en el aire | la palabra papel» (Emergencia I, vv. 13-14). Citando unas palabras del poeta Francis Ponge, Jean-Luc Nancy nos recuerda que escribir es escucha de una dicción que surge internamente y con la que el texto entra en resonancia (Nancy, 2004, 56). No es ninguna casualidad que la tercera y última parte del libro se titule precisamente "Emergencia". En ella, lo que emerge es algo 
nuevo que «[...] habla de antes | una tortuga sola que asoma la cabeza | en los mares del mito» (Emergencia II, vv. 10-12); algo que «viene desde todas las ideas» (Emergencia III, v. 1) y «lleva consigo todo su lenguaje» (Emergencia IV, v. 8); algo que «cuando saluda dice soy» (Emergencia IV, v. 13) y es «Voz de su cuerpo» (Emergencia VI, v. 2). El lema "voz" no aparece solo en esta última parte, sino que se encuentra sembrado a lo largo de todo el libro; con él, además, encontramos también términos que se refieren al aparato fonador.

En "Temperatura voz", el término "voz" aparece en posiciones disfóricas, donde la emisión de la phoné está ausente o imposibilitada: «qué dictados sin voz» (III, v. 14); «ahí angosta la palabra habitable | tajo en las cuerdas vocales flujo detenido» (VI, vv. 13-14); «la voz su verdad de espejismo | diciendo amor heno que arde» (VII, vv. 13-14); «abriendo a voz los tubos del mercurio | voz su sí no» (VIII, vv. 11-12); «boca surco de la memoria | quietud habilidad de los escombros» (XI, 1-2); «la voz lamiendo la temperatura sorda» (XI, v. 13); «el ojo su trabajo descriptible | qué proyecto labial» (XII, vv. 10-11). En "No Tengo", la palabra "voz" y los términos que atañen a la fonación se relacionan con la emisión de una phoné que ya no es tan angustiosa y por fin empieza a encontrar una forma: «responda su saliva en tanto voz» (I, v. 11); «[...] de todas | las palabras del día | sólo una es voz» (III, 6-9, 12-14); «el río pasa por la boca | alza la sed» (VI, vv. 13-14); «ahí con un olor entre los labios | viene planeta lleno» (VII, vv. 4-6); «y la humedad atenta al maquillaje | la voz lo incontestable» (VIII, vv. 5-6); «está llena de juegos | nunca sonó tan aguda su voz» (X, vv. 13-14); «el uno su voz múltiple | su delicado asco por el dos» (XII, vv. 5-6).

Sin embargo, es en "Emergencia" donde finalmente esta phoné consigue su forma propia, su cuerpo: el «de un niño como un deseo rebosante de voz» (VIII, v. 12). He aquí una phoné que ya no es solo lógos, puro pensamiento, sino materia rebosante, rezumante, sonora, viva. Una phoné que precede la palabra y emerge directamente del deseo, de las pulsiones, tal y como la piensa la perspectiva nietzscheana del gozo de la lengua reelaborada desde el punto de vista psicoanalítico por Julia Kristeva y Hélène Cixous. Esta perspectiva permite entender la voz, por un lado, como expresión de lo pre-verbal y, por otro, como aliada de la escritura, siempre en contra de una concepción sistemática y normativa del lenguaje que, no obstante el ejercicio compositivo autoimpuesto y 
precisamente a partir la manera en que lee estos textos, Mariano Peyrou pone radicalmente en tela de juicio. Su vocalización de los encabalgamientos "a medias" muestra el lugar donde la voz se hace eco y el lenguaje poético escapa de todo tipo de límite.

Es en este sentido, pues, que la phoné del autor puede emerger hasta llegar a la superficie de su escritura, entendida ahora como verdadera práctica del texto, permitiendo esa reflexión sonora, musical, de su materia constitutiva. Es desde la escucha - «su diapasón su oído» (Emergencia IX, v. 8)- que esta phoné organiza el texto subvirtiendo la pretensión del lenguaje de controlar la significación (Cavarero 2003, 147). Como en las lecturas, las pulsiones de lo puramente fónico siempre encuentran alguna fisura para estimular el lenguaje poético organizándolo de forma diferente y jugando así con el texto. El mismo Mariano Peyrou confirma esta perspectiva en la entrevista que me concedió primero al recordar el lema de Cixous que recita "el sentido es el opio del texto" (Cixous y Derrida 2004, 29) y luego cuando dice:

En realidad toda la poesía tiende hacia esa idea [...] Es como que vamos a jugar con las palabras o a trabajar con las palabras de una manera en que el sentido y lo que significa no sea lo que está en primer plano como hacemos siempre, siempre hacemos esto ya que lo que importa del lenguaje es lo que significa, ¿no? [...] pero en la poesía es como si dijéramos, desde que se trabaja con la rima, con la aliteración, con las estrofas, con los acentos, con todo esto, es como si dijéramos «el sentido importa, sigue importando, pero lo vamos a poner en segundo plano». Es la función poética de Jakobson, todo eso está allí. (Mistrorigo 2018, 191)

Sin duda todo ya está ahí: en aquella voz, phoné que es materia concreta del lenguaje, primordialmente sonora y siempre viva, física y resonante, a partir de la cual se mueven y concretan todas las posibles palabras que, no en tanto que ideas mudas, sino como notas musicales, llevan a la superficie el entramado del texto, su constante movimiento combinatorio, mostrando aquella infinita tensión propiamente poética entre las asperezas de cualquier molde a priori y las felices emergencias del juego de las palabras. Una voz que finalmente «[...] riega los líquidos» (Emergencia V, v. 4), una «voz de otro tacto» (Emergencia V, v. 7) que, sin embargo, siempre está «[...] en fuga [...]» (Emergencia V, v. 9). El mismo poeta se pregunta, después de todo, «quién conoce su voz 
su propia» (XI, v. 12) admitiendo que a menudo es algo que se ignora.

\section{Bibliografía}

Agamben, Giorgio. Categorie italiane. Studi di poetica. Venecia: Marsilio, 1996.

Agamben, Giorgio. Che cos'è la filosofía. Macerata: Quodlibet, 2016.

Agamben, Giorgio. Idea de la prosa. Barcelona: Ediciones Península, 1989.

Agamben, Giorgio. L'uso dei corpi. Vicenza: Neri Pozza, 2014.

Barthes, Roland. Lo obvio y lo obtuso. Imágenes, gestos, voces. Barcelona: Paidós, 1986.

Canteli, Marco. "De lo circunstancial: entrevista a Mariano Peyrou". Sie7e de Sie7e, Revista de escritura y poética, "reticencia" 11 marzo 2009. http://www.7de7.net/dinamicas/general.php?id_contenido=249\&id_seccion=2

Cavarero, Adriana. A più voci. Filosofia dell'espressione vocale. Milán: Feltrinel Agamben, Giorgio li, 2003.

Cixous, Hélène y Derrida, Jacques. Lengua por venir. Barcelona: Icaria, 2004.

Dolar, Malden. A voice and nothing more. Cambridge, Massachusetts: The MIT Press, 2004.

Kristeva, Julia. La rivoluzione del linguaggio poetico. L'avanguardia nell'ultimo scorcio del XIX secolo: Lautréamont e Mallarmé. $1^{\text {a }}$ Ed. Venecia: Marsilio, 1979

Kristeva, Julia. La rivoluzione del linguaggio poetico. L'avanguardia nell'ultimo scorcio del XIX secolo: Lautréamont e Mallarmé. Milán: Spirali, 2006.

Mistrorigo, Alessandro. Phonodia. La voz de los poetas, uso crítico de sus grabaciones y entrevistas. Venecia: Edizioni Ca' Foscari, 2018.

Nancy, Jean-Luc. All'ascolto. Milán: Raffaello Cortina, 2004.

Nowell-Smith, David. On Voice in Poetry. The Work of Animation. Londres: Palgrave MacMillan, 2015

Peyrou, Mariano. Temperatura Voce. Ed. Alessio Brandolini. Roma: Fili D’Aquilone, 2010.

Rodríguez, Ildefonso. "Presentación del libro Temperatura voz. Mariano Peyrou, 2010. https://www.facebook.com/notes/pre-textos/presentaci\%C3\%B3n-del-librotemperatura-voz-de-mariano-peyrou-por-ildefonsorodr\% $\% 3 \%$

ADguez/126860650684956/

Samoilovich, Daniel. "Una grammatica non euclidea". Temperatura Voce. Mariano Peyrou. Ed. Alessio Brandolini. Roma: Fili D’Aquilone, 2010. 5-9.

Tsur, Reuven. Poetic Rhythm: Structure and performance: an empirical study in cognitive poetics. Brighton: Sussex Academic Press, 2012. 